\title{
Erratum to: Papilloma on Core Biopsy: Excision vs. Observation
}

\section{Faina Nakhlis ${ }^{1}$, Nasim Ahmadiyeh ${ }^{2}$, Susan Lester ${ }^{3}$, Sughra Raza $^{4}$, Parisa Lotfi ${ }^{4}$, and Mehra Golshan ${ }^{1,5}$}

${ }^{1}$ Department of Surgery, Brigham and Womens Hospital, Boston; ${ }^{2}$ Department of Surgery, University of California, San Francisco, San Francisco; ${ }^{3}$ Department of Pathology, Brigham and Women's Hospital, Boston; ${ }^{4}$ Radiology, Brigham and Women's Hospital, Boston; ${ }^{5}$ Department of Surgery, Harvard Medical School, Brigham and Women's Hospital, Boston

\section{ERRATUM TO: ANN SURG ONCOL}

DOI 10.1245/S10434-014-4091-X

In the results section of the abstract, in 45 IPs without atypia, 3 cancers were seen (upgrade $6.7 \%$ ). The upgrade was erroneously stated as $6 \%$.

The online version of the original article can be found under doi: 10 . 1245/s10434-014-4091-x.

(C) Society of Surgical Oncology 2014

Published Online: 2 December 2014

M. Golshan

e-mail: MGOLSHAN@PARTNERS.ORG 